\section{Commentary: Rheumatic mitral valve disease: Repair when you can, replace when you can't?}

\author{
Michele De Bonis, MD, FESC, FAHA, and \\ Davide Carino, MD
}

Rheumatic heart disease is still endemic, particularly in low-income countries, where it is mainly observed in young patients, often in its acute phase. By contrast, in developed countries, it is seen at a later age (mean 50-55 years), as a stabilized process. The issue of repair versus replacement in rheumatic mitral valve (MV) disease has been debated for long time. Several papers have reported better survival with repair, ${ }^{1,2}$ despite its greater reoperation rate. ${ }^{1}$ Recently, $\mathrm{Fu}$ and coworkers ${ }^{3}$ reported that $\mathrm{MV}$ repair is associated with better survival and lower rates of valve-related events than replacement, regardless of the type of prosthesis. Others have confirmed that valve repair, in selected patients, leads to comparable survival but superior valve-related outcomes. ${ }^{4}$ The study by Chen and colleagues ${ }^{5}$ raises again a word of caution against this trend in favor of repair, emphasizing that this approach leads to greater reoperation rates without survival benefit. These findings, worthy of consideration, should be interpreted in the light of the following observations.

First, this study was based on national insurance International Classification of Diseases codes. Therefore, important data like left and right ventricle size/function, systolic pulmonary artery pressure, atrial fibrillation, intraoperative findings, and surgical techniques were missing, making unclear whether the 2 groups were really comparable.

The follow-up duration (median 6 years) might have been insufficient to detect bioprosthetic deterioration as well as the real incidence of mechanical prosthesis complications

\footnotetext{
From the Division of Cardiac Surgery, "Vita-Salute" San Raffaele University, IRCCS San Raffaele Hospital, Milan, Italy.

Disclosures: The author reported no conflicts of interest.

The Journal policy requires editors and reviewers to disclose conflicts of interest and to decline handling or reviewing manuscripts for which they may have a conflict of interest. The editors and reviewers of this article have no conflicts of interest.

Received for publication Aug 18, 2020; revisions received Aug 18, 2020; accepted for publication Aug 18, 2020; available ahead of print Aug 24, 2020.

Address for reprints: Michele De Bonis, MD, FESC, FAHA, Division of Cardiac Surgery, "Vita-Salute" San Raffaele University, IRCCS San Raffaele Hospital, Via Olgettina 60, 20132 Milan, Italy (E-mail: debonis.michele@hsr.it). J Thorac Cardiovasc Surg 2022;164:74-5 $0022-5223 / \$ 36.00$

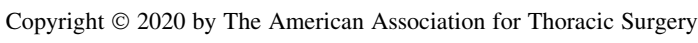
https://doi.org/10.1016/j.jtcvs.2020.08.062
}

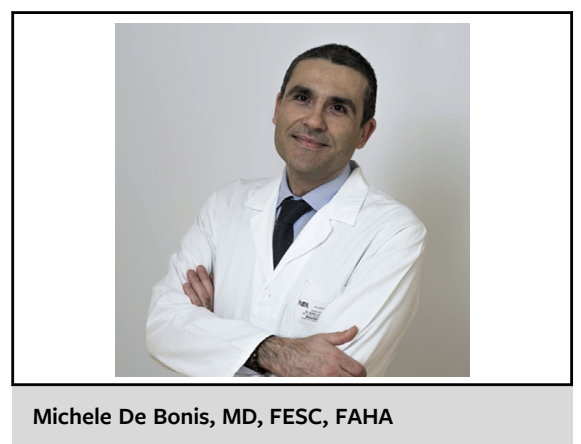

CENTRAL MESSAGE

Repairing rheumatic mitral valves remains challenging. The choice between repair and replacement must be carefully tailored to the patient, the complexity of the lesion, and the surgeon's expertise.

and the related implications on long-term survival. The study population included mainly patients with mixed lesions, which are usually more challenging to repair. Finally, most of the improved outcomes with repair have been reported by single centers with great experience in this field. In this study, hospitals with larger volumes had a greater repair rate but similar results compared with smaller centers. This finding is difficult to explain and may be due to patient selection bias. Nonetheless, it is not possible to exclude that the better outcomes usually achieved by the most-experienced centers tend to be somehow masked in such national-based studies.

Despite recent technical advances, repairing rheumatic mitral valves remains challenging. The choice between repair and replacement must be carefully tailored to the patient, the complexity of the lesion, and the expertise of the surgeon. It should remain the preferred option in the presence of favorable echocardiographic features such as preserved mobility at least of the anterior leaflet, no or minimal calcifications, and sufficiently long residual chordae tendineae. Long-term results may be better than prosthetic valves, despite a greater rate of reoperation as compared with degenerative MV disease. Young age, desire for pregnancy, poor compliance to anticoagulation for mechanical valves, and inadequate health care systems may be good reasons to push the limits of a difficult repair attempt. Rheumatic mitral valves with unfavorable echocardiographic features (mixed lesions, heavy calcifications, 
papillary muscles attached to the leaflets) and/or previous percutaneous commissurotomy are unlikely to be repaired with the perspective of a reasonable durability. Therefore, they should be replaced, possibly with a bioprosthesis, in view of the valve-in-valve perspective, particularly in relatively elderly patients.

\section{References}

1. Yau TM, El-Ghoneimi YA, Armstrong S, Ivanov J, David TE. Mitral valve repair and replacement for rheumatic disease. J Thorac Cardiovasc Surg. 2000;119:53-60.
2. Kim JB, Kim HJ, Moon DH, Jung SH, Choo SJ, Chung CH, et al. Long-term outcomes after surgery for rheumatic mitral valve disease: valve repair versus mechanical valve replacement. Eur J Cardiothorac Surg. 2010;37: 1039-46.

3. Fu J, Li Y, Zhang H, Han J, Du J, Meng X. Outcomes of mitral valve repair compared with replacement for patients with rheumatic heart disease. J Thorac Cardiovasc Surg. February 14, 2020 [Epub ahead of print].

4. Kim WK, Kim HJ, Kim JB, Jung SH, Choo SJ, Chung CH, et al. Clinical outcomes in 1731 patients undergoing mitral valve surgery for rheumatic valve disease. Heart. 2018;104:841-8.

5. Chen S-W, Chen C-Y, Chien-Chia V, Chou A-H, Cheng Y-T, Chang S-H, et al Mitral valve repair versus replacement in patients with rheumatic heart disease J Thorac Cardiovasc Surg. 2022;164:57-67.e11. 